\title{
A conceptual model of the impacts of quality components of a health department website on students' health literacy at Semnan University of Medical Sciences
}

\author{
Mehdi Kahouei ${ }^{1}$, Ali Mohammadi ${ }^{2}$, Javad Zarei ${ }^{3}$, Nasrollah Nasr Heidarabadi ${ }^{4}$, Ali Valinejadi ${ }^{5}$
}

${ }^{1}$ Ph.D. of Health Information Management, Associate Professor, Social Determinants of Health Research Center, School of Allied Medical Sciences, Semnan University of Medical Sciences, Semnan, Iran

${ }^{2}$ Ph.D. of Health Information Management, Assistant Professor, Department of Health Information Technology, Paramedical School, Kermanshah University of Medical Sciences, Kermanshah, Iran

${ }^{3} \mathrm{Ph}$.D. of Health Information Management, Assistant Professor, Department of Health Information Technology, School of Allied Medical Sciences, Ahvaz Jundishapur University of Medical Sciences, Ahvaz, Iran

${ }^{4}$ Ph.D. of Medical Informatics, Department of Information Technology, Shefa Neuroscience Research Center, Khatam-ol-Anbia Hospital, Tehran Iran

${ }^{5} \mathrm{Ph}$.D. of Health Information Management, Assistant Professor, Social Determinants of Health Research Center, School of Allied Medical Sciences, Semnan University of Medical Sciences, Semnan, Iran

\section{Type of article: Original}

\begin{abstract}
Background: People with poor health literacy are those who have less knowledge about disease management and health promotion behaviors, and generally have poorer health status.

Objective: The aim of this study was to investigate the impact of qualitative components of the health website of Semnan University of Medical Sciences on the students' health literacy.

Methods: This study was performed on 529 medical and allied health students in schools affiliated to Semnan University of Medical Sciences, Iran in 2016-2017. A researcher-made questionnaire and standard questionnaire were used. Descriptive statistics and regression test were used by SPSS 19 to analyze data in significance level of 0.01 .

Results: The findings showed that there were poor relationships between communications in the health website and health literacy $\left(\mathrm{R}^{2}=0.265, \mathrm{~B}=0.50\right)$, between understanding of concepts in the health website and health literacy $\left(\mathrm{R}^{2}=0.259, \mathrm{~B}=0.38\right)$ and patient centeredness in the health website and health literacy $\left(\mathrm{R}^{2}=0.241\right.$, $\mathrm{B}=0.30)$.

Conclusion: It is concluded that the empowerment of students' health literacy through the University Health Department website can be realized when the health department website is used as a tool for learning and the website is much more active in social marketing in the field of health.

Keywords: Models, Theoretical; Health literacy; Universities; Learning; Students
\end{abstract}

\section{Introduction}

The advent of information technology has had profound effects on human life. Perhaps education and learning have been affected by that more than other areas. Now, everyone can get access to his/her needed information wherever and whenever they wish (1). The World Wide Web, as one of the most prominent communication and information technologies, represents the technological advancement of today's human being; their role in making social changes is undeniable (2). One reason for using the World Wide Web is to achieve information of health services. People promote their literacy in the field of health issues through the Internet (3). Health literacy represents the link

\section{Corresponding author:}

Assistant Professor Dr. Ali Valinejadi, Social Determinants of Health Research Center, School of Allied Medical Sciences, Semnan University of Medical Sciences, Semnan, Iran.

Tel: +9823-33614664, Fax:+9823-33614664, Email: valinejadi.a@semums.ac.ir

Received: January 01, 2018, Accepted: March 10, 2018, Published: May 2018

iThenticate screening: March 11, 2018, English editing: April 13, 2018, Quality control: April 15, 2018

This article has been reviewed / commented by eight experts

(C) 2018 The Authors. This is an open access article under the terms of the Creative Commons Attribution-NonCommercialNoDerivs License, which permits use and distribution in any medium, provided the original work is properly cited, the use is non-commercial and no modifications or adaptations are made. 
between literacy and health. People with poor health literacy are those who have less knowledge about disease management and health promotion behaviors and generally have poorer health status (4). Inadequate health literacy increases the inefficacy of health care. So low-educated people use less preventive services and are at risk (5). More emphasis on well-informed and active healthcare users has led to ensuring that people's access to health information is proposed as an important goal for health services (6). Many studies consider the content of health-related websites to be the most important factor of the success in achieving health information (7). Due to the increasing growth of information on websites, designing and creating a website that in the best way satisfies the users' needs for health literacy seems necessary; so the lack of proper design of information content leads to the users' waste of time and money spent inefficaciously (8). University websites are the most important communication tools for introducing and communicating with universities at national and international levels. Regular reviewing and evaluating websites structurally and contently, followed by recognizing their strengths and weaknesses, will provide a good strategy for policy and decision making (9). The content of a university website includes information and capacities and services that a university offers through a website. Considering that the main users of such websites are mostly faculty members and students, the content of these websites should be such that they can meet the information needs of their users (10). Therefore, the aim of this study was to investigate the impact of qualitative components of the health website of Semnan University of Medical Sciences on the students' health literacy.

\section{Material and Methods \\ 2.1. Sample and setting}

Participants in this study were medical and allied health students of Semnan University of Medical Sciences in Iran. The research was conducted over five months, from December 2016 to May 2017. The census method was used and the sampling method was not used in the current study. A total of 832 questionnaires were distributed; 529 were returned, which represented a response rate of $63.5 \%$.

\subsection{Measures}

The questionnaire used in this study was developed by the authors, after reviewing the related literatures. The questionnaire included three parts. The first part included 7 questions and was related to demographic information (sex, age, education, computer skills, general health status, the frequency of the use of website and the frequency of the use of Telegram application. The second part was divided into three sections; the first section included 3 questions and comprised a scale to measure the attitudes of the students in relation to the understanding of concepts in the website (the understanding of physical, mental and emotional health, the understanding of scientific and medical information, the website's awareness of students' needs); the second section included 5 questions and measured communications in the website (communication with other people in health issues, obtaining healthrelated information, referring to other websites to answer to health-related questions, communication with website by telegram, inserting questions related to health topics within the web site and to find their answers) ; and the third section comprised 4 questions and evaluated patient centeredness in the website (making informed decisions to solve health problems, evaluating the validity of information resources related to health issues and evaluating health care services offered, patients to be supported by their friends and family). Attitudes on the second part were measured on a 5-point Likert type scale, where completely disagree $=1$, disagree $=2$, neither disagree nor agree $=3$, agree $=4$ and completely agree $=5$. The questionnaire was reviewed for content validity through the content validity index (CVI), and evaluated by 10 experts, who offered feedback in relation to the simplicity and clarity of questions, and the relationship between questions. The questionnaire was then pilot tested on 35 students, randomly selected from medical and allied health schools. Participants in the pilot study were excluded from the study. Internal consistency was expressed as Cronbach's alpha 0.743 for the section of the understanding of concepts in the website, 0.815 for the section of communications in the website; and 0.687 for the section of patient centeredness in the website. Next, further revisions were made and some statements were rephrased. The third part was an adult health-literacy questionnaire designed by Montazeri et al. (11). The third part was divided into five sections. The first section comprised 6 items to measure the attitudes of the students in relation to the impact of the health department website on the students' access to health information. Attitudes on each item were measured on a 5-point Likert type scale, where Never $=1$, rarely $=2$, sometimes $=3$, most of the time $=4$ and always $=5$. The second section included 4 items related to reading health information on websites. Attitudes on each item were measured on a 5-point Likert type scale, where very hard $=1$, hard $=2$, not easy and not hard $=3$, easy $=4$ and very easy $=5$. The third section included 7 items related to comprehension of health information. Attitudes on each item were measured on a 5-point Likert type scale, where never $=1$, rarely $=2$, sometimes $=3$, most of the time $=4$ and always $=5$. The fourth section comprised 3 items related to the assessment of health information. The fifth section included 13 items related items 
to decision making and usage of health information. Attitudes on the third, fourth and fifth sections were measured on a 5-point Likert type scale, where never $=1$, rarely $=2$, sometimes $=3$, most of the time $=4$ and always $=5$.

\subsection{Procedure}

The anonymous questionnaire was distributed among students in medical and allied health schools and they were asked to complete the questionnaire and return them to the researcher within 72 hours.

\subsection{Data analysis}

To determine the distributions of responses, SPSS version 19 (SPSS Inc., Chicago, Illinois, USA) was used to perform descriptive statistics. Regression test were used to analyze data in significance level of 0.01 .

\subsection{Ethical consideration}

Ethics approval was obtained from the Ethics Committee of Semnan University of Medical Sciences (Ref. no.: IR.SEMUMS.REC.1395.204). A covering letter was prepared for distribution with the survey document, which described the purposes of the study and explained that a response to the survey would indicate the consent of the participant to take part in the research. It also assured participants of the confidentiality of their responses.

\section{Results}

The participants' mean age was 21.37 years. Of these, $304(57.5 \%)$ were female, $353(67.1 \%)$ were undergraduates, and $206(39 \%)$ had moderate computer skills. In all, 271 (51.2\%) had good general health. As regards website use, $230(43.5 \%)$ used the website monthly, and $315(59.5 \%)$ used Telegram daily. The findings showed that there was a poor relationship between communications in the health website and health literacy $\left(\mathrm{R}^{2}=0.265\right)$ (Figure 1). There was a poor relationship between understanding of concepts in the health website and health literacy $\left(\mathrm{R}^{2}=0.259\right)$ (Figure 2). There was a poor relationship between patient centeredness in the health website and health literacy $\left(\mathrm{R}^{2}=0.241\right)$ (Figure 3$)$. The findings showed that there were significant correlations between the qualitative elements of the health website $(\mathrm{p}<0.001)$ (Figure 4$)$.

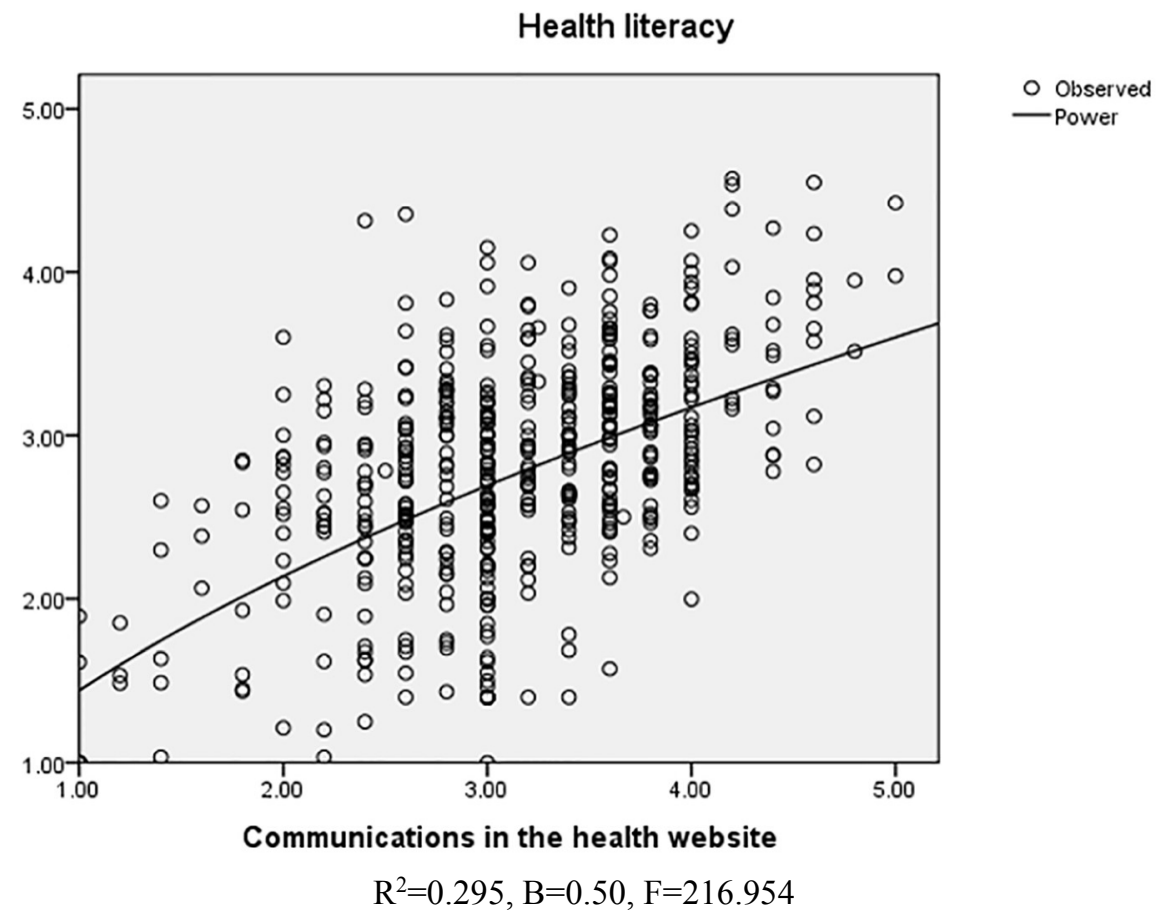

Figure 1. Regression between communications in the health website and the health literacy among the study subjects. 


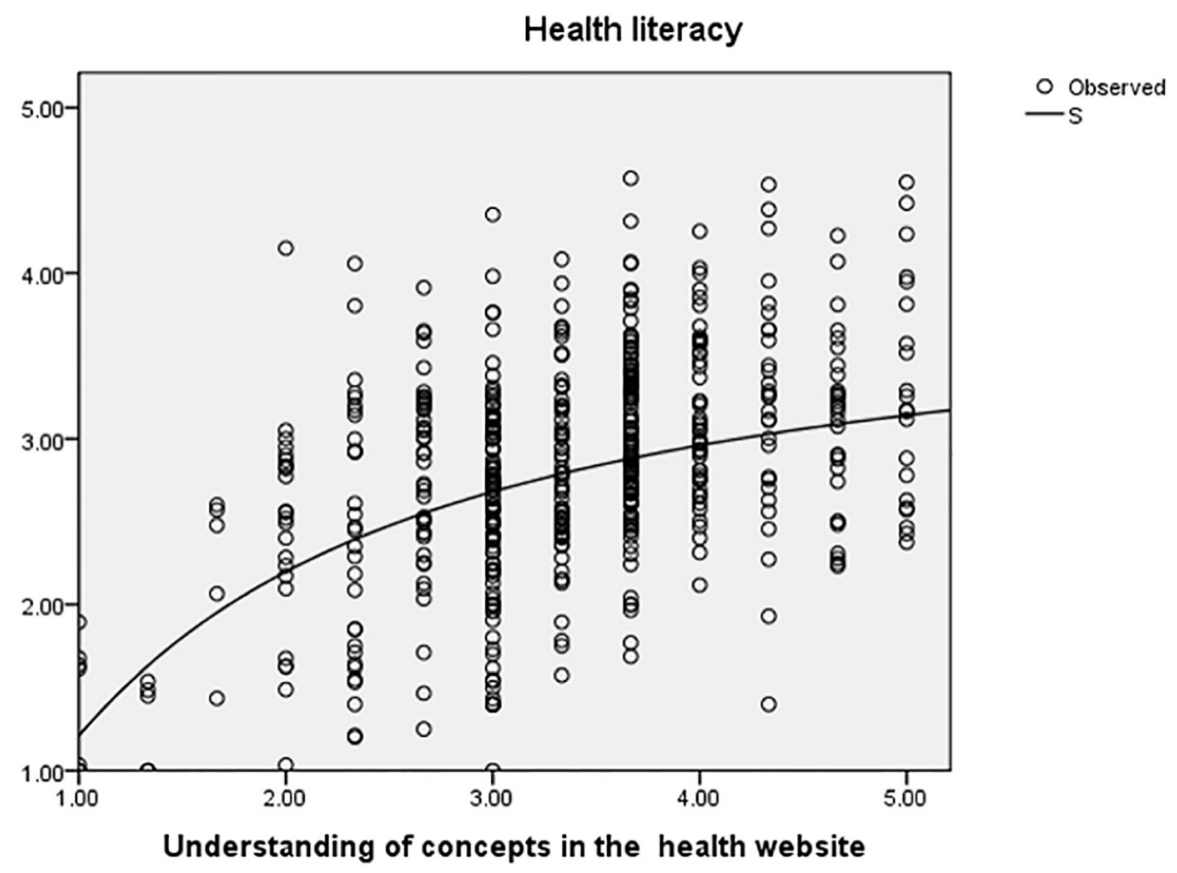

$\mathrm{R}^{2}=0.259, \mathrm{~B}=0.38, \mathrm{~F}=180.892$

Figure 2. Regression between the understanding of concepts in the health website and the health literacy among the study subjects.

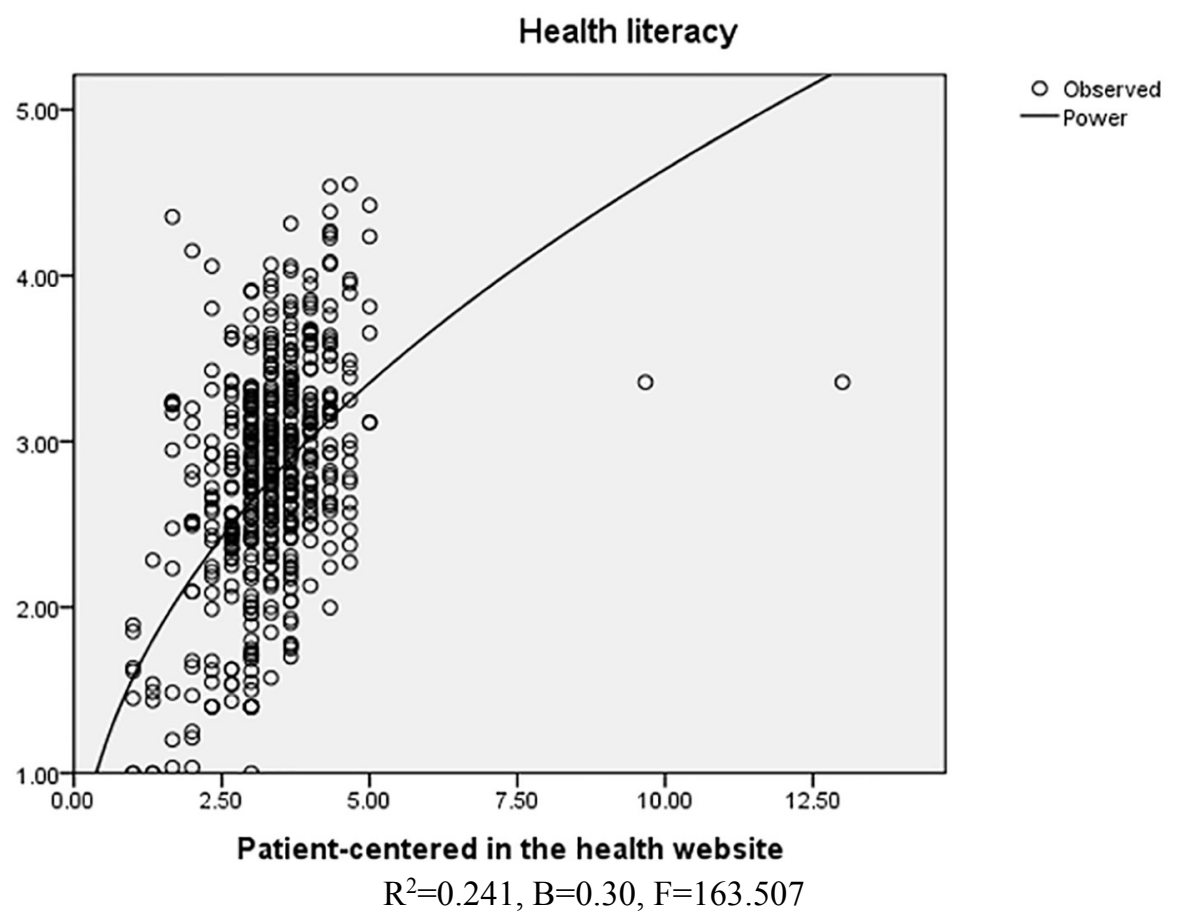

Figure 3. Regression between patient centeredness in the health website and the health literacy among the study subjects. 


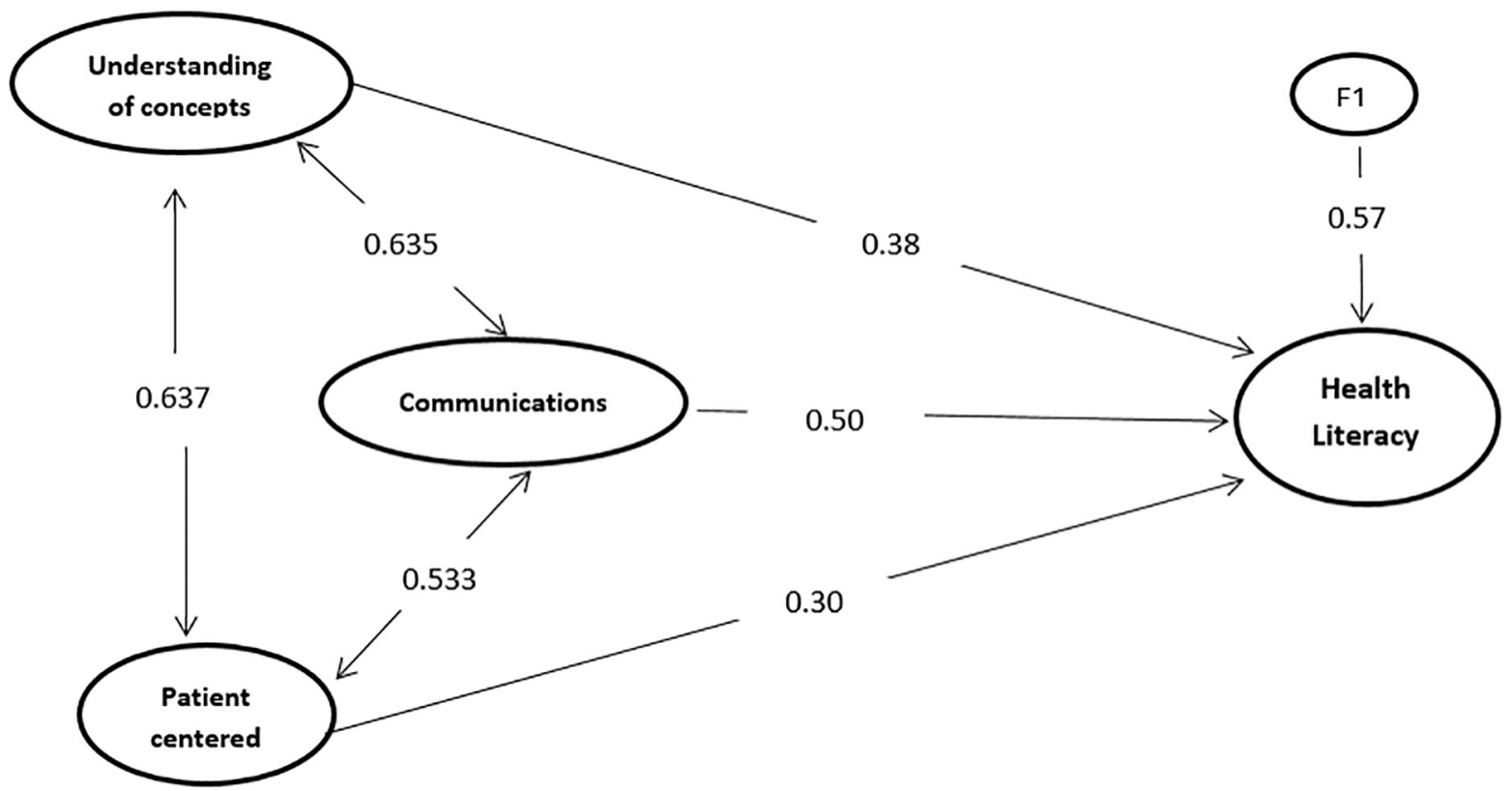

Figure 4. Correlations between the qualitative elements of the health website and their relationships with the students' literacy.

\section{Discussion}

This study was performed to investigate the impact of qualitative components of the health website of Semnan University of Medical Sciences on the students' health literacy. Although there was a poor relationship between the quality of the website and students' health literacy, however, the results of this study showed that $50 \%$ of change of health literacy of students through the health website depends on the status of communication between users in the website space. It seems that the strong interactions between users on the web, lead the feedback mechanism and the tools for sharing information among students to become user-friendly. This helps to establish an active interaction among students, be provided their satisfaction with health information, and be satisfied that their needs are predicted in this regard (8). Devine's study results confirm the findings of this study. He found that website users could easily ask each other questions at the website, and answer each other until they refer to another website (12). Findings show that interactive services such as chat rooms or questioning online by the help of websites make health information accessible to all (10). Students, through the website, have easy access to health information such as diseases and their symptoms, physical and behavioral abnormalities, prevention of diseases and health promotion, and learning therapeutic procedures (13). Reading is a complex skill that involves understanding and thinking (14). This study showed that there was a poor relationship between the understanding of concepts on the website and the students' health literacy; so that $38 \%$ of changes in improving the health literacy of the students through the website are associated with the students' perceptions of the concepts found on the university health website. It seems that if health information available on the website is based on medical protocols and experts' opinions, this will affect their ability to learn the content of the text and find out the message available on the website. (15) Regarding that reading is constituted from two processes related to one another, such as knowing a word (or the speech), as well as understanding that word (16), hence the findings of this study reveal that students learn, by the help of a website, to be informed about health information through the text. Students' familiarity with health concepts is one of the characteristics that contributes to the ability of students to engage successfully with a health care system (17). As a result, the university health website should necessarily regulate the connection with students based on their actual health literacy. In this regard, the simple and understandable written contents can be used on the website. Otherwise, the average literacy of students will remain at the boundary level of literacy. Students with this level of health literacy will often have an erroneous understanding of health information and fail to be aware of their rights and responsibilities (18). The findings indicated that $30 \%$ of change in students' health literacy is associated to the patient-centeredness of the website. This study showed that there was a poor relationship between this aspect of the quality of the website and the students' health literacy. It seems that the existence of evidence-based information on the website in order to provide quality, complete, valuable and accurate information with the aim of empowering students leads them to identify health information and select a health activity for solving a Health Problem for Self- 
Care (19). Other studies have also shown that some users did not use the website because the information sources of the websites were unclear $(20,21)$. The results indicate that the proper architecture of the information on the website guides significantly the students to an environment where the needed information is easily accessible (21); in that environment the students correctly perceive health information and properly assess health services. Finally, students will be more confident in the health website and make informed decisions to solve health and medical problems. Hazara \& Bhandari found that the reasons for not accessing the information on the website were the following: there was a lot of information on website pages, the needed information was not easily found, there was no communication between the websites of each section (22). T findings show that each component of the website's quality affects the students' health literacy and from these components, the website's communication feature is more effective on the students' health literacy.

\section{Strengths and limitations}

This study has several implications. First, the results of this study showed that empowering students to benefit from the complex medical system, reading, listening, analyzing, deciding, and the ability to use these skills in health settings through the university health website occurs when the university health website contains well-written and available teaching materials for students. Secondly, the university health website should be compatible with its internal users. So if a university wants to increase the health literacy of students through its website, it should use a user-centric, comprehensive approach to designing and developing a website. This study has a number of limitations, the first limitation is that the study used a user-driven methodology to assess the quality of the website of the health sector, which is only perceived by users, and that is not easy, because the quality of the website cannot be evaluated based on the understanding of users. The second limitation is related to the low number of participants. The study would be better conducted with a high volume of participants. The third limitation is that there is no golden standard to assess the functionality of a website, so different methods of gauging, measure different as pects of a given website's capabilities. In spite of the above limitations, this study emphasizes the importance of training and designing a university website for the health department of a university, using e-health software.

\section{Conclusions}

It is concluded that the empowerment of students' health literacy through the University Health Department website can be realized when the health department website is used as a tool for learning and the website is much more active in social marketing in the field of health.

\section{Acknowledgments:}

Research reported in this publication was supported by a grant [ref. no.: 1187] from Semnan University of Medical Sciences, Semnan, Iran. We would like to thank the Clinical Research Development Unit of Kowsar and Amiralmomenin Educational, Research and Therapeutic Centers of Semnan University of Medical Sciences for providing facilities to this work.

\section{Conflict of Interest:}

There is no conflict of interest to be declared.

Authors' contributions:

All authors contributed to this project and article equally. All authors read and approved the final manuscript.

\section{References:}

1) Khan HU, Awan MA. Possible factors affecting internet addiction: a case study of higher education students of Qatar. Int J Bus Inf Syst. 2017; 26(2): 261-76. doi: 10.1504/IJBIS.2017.086339.

2) Sandhu SK. An interpretative flexibility analysis of internet as a learning practice among tertiary education students. Int J Educ Manag Study. 2016; 6(4): 420.

3) Lawrentschuk N, Abouassaly R, Hewitt E, Mulcahy A, Bolton DM, Jobling T. Health information quality on the internet in gynecological oncology: a multilingual evaluation. Eur J Gynaecol Oncol. 2016; 37(4): 478-83. doi: 10.1245/s10434-011-2137-x.

4) Couture ÉM, Chouinard MC, Fortin M, Hudon C. The relationship between health literacy and quality of life among frequent users of health care services: a cross-sectional study. Health Qual Life Outcomes. 2017; 15(1): 137. doi: 10.1186/s12955-017-0716-7. PMID: 28683743 PMCID: PMC5500997. 
5) Manganello J, Gerstner G, Pergolino K, Graham Y, Falisi A, Strogatz D. The relationship of health literacy with use of digital technology for health information: implications for public health practice. J Public Health Manag Pract. 2017; 23(4): 380-7. doi: 10.1097/PHH.0000000000000366. PMID: 26672402.

6) Samadbeik M, Garavand S, Sohrabi Zadeh M, Koshki N, Mohammadi Z. Health Literacy Instruments for Computer-Based Applications: A Review Article. J Biomed Health Inform. 2015; 2(3): 195-203.

7) Trivedi N, Kossakowski T, Berneis M, Tischler DH, Daluiski A. Evaluation of Patient Information Posters Directing Patients to Access a Health Information Website. JAMA Surg. 2016; 151(9): 880-1. doi: 10.1001/jamasurg.2016.1235. PMID: 27305654.

8) Abedi S, Khajouei R, Ahmadian L, Kaveh S. Information Content of the Websites of Health Information Management and Technology, and Medical Records Departments in Iranian Medical Universities. Health Inf Manag. 2014; 11(4): 399.

9) Farhadi A, Amiri MR, Karami S, Omidi Z, Safipour Afshar A. Evaluation of schools' Websites of Hamedan University of Medical Sciences based on webometrics criteria in 2014. Pajouhan Scientific J. 2015; 13(3): 31-9.

10) Sowter J, Astin F, Dye L, Marshall P, Knapp P. Assessment of the quality and content of website health information about herbal remedies for menopausal symptoms. Maturitas. 2016; 88: 16-22. doi: 10.1016/j.maturitas.2016.02.016. PMID: 27105691.

11) Montazeri A, Tavousi M, Rakhshani F, Azin SA, Jahangiri K, Ebadi M, et al. Health Literacy for Iranian Adults (HELIA): development and psychometric Properties. Payeshe. 2014; 13(5): 589-99.

12) Devine T, Broderick J, Harris LM, Wu H, Hilfiker SW. Making Quality Health Websites a National Public Health Priority: Toward Quality Standards. J Med Internet Res. 2016; 18(8): e211. doi: 10.2196/jmir.5999. PMID: 27485512, PMCID: PMC4987491.

13) Zhang Y, Zhang F, Hu P, Huang W, Lu L, Bai R, et al. Exploring health literacy in nursing students of Chongqing, China: a cross-sectional survey using the health literacy questionnaire. The Lancet. 2016; 388: S99. doi: 10.1016/S0140-6736(16)32026-8.

14) Hutchinson N, Baird GL, Garg M. Examining the reading level of internet medical information for common internal medicine diagnoses. Am J Med. 2016; 129(6): 637-9. doi: 10.1016/j.amjmed.2016.01.008. PMID: 26829438.

15) Wang W, Sun R, Mulvehill AM, Gilson CC, Huang LL. Handling Internet-Based Health Information: Improving Health Information Web Site Literacy Among Undergraduate Nursing Students. J Nurs Educ. 2017; 56(2): 110-4. doi: 10.3928/01484834-20170123-08. PMID: 28141885.

16) Wilson-Lopez A, Strong K, Sias C. Critical literacy, disciplinary literacy: Reading the engineeringdesigned world. Theory Into Pract. 2017; 56(4): 238-45. doi: 10.1080/00405841.2017.1389219.

17) Mullan J, Burns P, Weston K, McLennan P, Rich W, Crowther S, et al. Health literacy amongst health professional university students: a study using the Health Literacy Questionnaire. Educ Sci. 2017; 7(2): 54. doi: 10.3390/educsci7020054.

18) Khosravi A, Ahmadzadeh Kh, Arastoopoor Sh, Tahmasbi R. Health Literacy Levels of Diabetic Patients Referred to Shiraz Health Centers and Its Effective Factors. Health Inf Manag. 2015; 12(2): 205.

19) Siegel M, Tukan N, Abbott J. Medical Students Can Improve Health Literacy: Training Students to Educate Patients About Obstetric Venous Thromboembolism Prophylaxis. J Gynecol Obstet. 2017; 130: 48S-9S. doi: 10.1097/01.AOG.0000525749.69767.9c.

20) Limb M. Website aims to help people understand health research. Br Med J. 2016; 354: i4403. doi: 10.1136/bmj.i4403. PMID: 27510722.

21) Sahusilawane W, Hiariey LS. The Role of Service Quality toward Open University Website on The Level of Student Satisfaction. J Educ Learn. 2016; 10(2): 85-92. doi: 10.11591/edulearn.v10i2.3238.

22) Hazara AM, Bhandari S. Barriers to patient participation in a self-management and education website Renal Patient View: A questionnaire-based study of inactive users. Int J Med Inform. 2016; 87: 10-4. doi: 10.1016/j.ijmedinf.2015.12.004. PMID: 26806707. 